\title{
Economic Crisis and Peri-Urban Agriculture: A Socio-Environmental Vision
}

\author{
Luca Salvati ${ }^{1, *} \&$ Silvia Pili ${ }^{2}$ \\ ${ }^{1}$ CREA, Research Centre for Forestry and Wood, Viale S. Margherita 80, I-52100 Arezzo, \\ Italy \\ 2 Department of Architecture and Project, Sapienza University of Rome, Via Flaminia 369, \\ I-00196 Rome, Italy \\ *Corresponding author: Council for Agricultural Research and Economics (CREA), Via della \\ Navicella 2-4, I-00184 Rome, Italy. E-mail: luca.salvati@crea.gov.it
}

Received: December 9, 2017 Accepted: January 5, 2018 Published: January 24, 2018

doi:10.5296/jsr.v9i1.12268ＵRL: https://doi.org/10.5296/jsr.v9i1.12268

\begin{abstract}
In wealthiest countries, urban sprawl and peri-urban agricultural landscapes are strictly interconnected issues, with dispersed urban expansion causing inherent land-use conflicts. Interpreting latent socioeconomic processes at the base of peri-urban agriculture in southern Europe may benefit from a thorough analysis of metropolitan dynamics of growth and change, considering together morphological and functional issues. The approach proposed in this study is intended to provide an overview of new strategies for food production in highly fragmented landscapes, investigating the point of view of local actors operating in the primary sector. A preliminary survey carried out in the Athens' metropolitan region, Greece, provides a knowledge base to identify apparent and latent trends in peri-urban farming and the mutual implications for farmers and citizens.
\end{abstract}

Keywords: Urban fringe, Local communities, Land-use, Mediterranean region 


\section{Introduction}

The regional context and the underlying socioeconomic determinants can be considered as the basis of landscape degradation. This phenomenon is a particularly relevant issue in the Mediterranean region, giving rise to natural disasters - including landslides - and economic/ecological degradation of sensitive and ecologically fragile soils (Conacher 2000). The Mediterranean region is one of the most exposed to the combined effects of urban growth and climate change (Soulard et al., 2016). With the purpose of evaluating land degradation, several approaches have been recently developed, integrating official statistics and field surveys into methodologies grounded on vulnerability indices. Additional methods consist in the application of computational approaches for the description of degraded landscapes, proposing a multi-scale point of view. For example, the environmental vulnerability of Mediterranean land has been frequently assessed through quality indicators of climate, soil, vegetation and land-use, or through a comprehensive analysis of the human factors affecting population growth and soil conservation (Cori and Lemmi, 2001).

The permanent assessment of (changing) local contexts takes particular interest when referring to the recent evolution of socio-environmental processes. On the one hand, territorial transformations involving the reciprocal relations between humans and environment that are responsible of land, soils, landscape and, more generally, of the degradation of natural resources, can be evaluated retrospectively, thus providing a basis for the assessment of sustainable land management (Faggi, 1991). On the other hand, a qualitative land-use assessment based on visual analysis protocols is essential for identification of latent land-use changes, also emphasizing the role of local communities in these transformations, especially in rural, marginal areas.

Based on these considerations, the present contribution integrates different disciplinary visions that have characterized the recent literature in socio-environmental issues with the final aim to reach an improved interpretation of complex ecological themes under different socioeconomic background conditions. Starting from land degradation as a conceptual referent, this research moves to the identification of latent changes evaluable through visual perception approaches: as more traditional quantitative methods, this approach is proposed to assess environmental and territorial complexity, introducing a mixed protocol that can enhance both research experiences (qualitative and quantitative).

This study refers to the theoretical-conceptual framework of the 'Environmental sociology', with specific reference to the theorization of the New Ecological Paradigm (NEP) formulated by Catton and Dunlap (1978) and the analytical framework subsequently developed by the same authors. Catton and Dunlap theory provided "[...] the first attempt to elaborate a theoretical framework for a sociological consideration of the complex and almost infinite relations between society and the environment [...]" (Beato, 1998, p. 20). Dunlap et al. (2002) proposed the New Ecological Paradigm Scale revising the original NEP, through the inclusion of a wider range of ecological issues, offering a balanced set of pro- and anti-NEP items at the same time. As resumed by Atav et al. (2015) the NEP-Scale is based on the following items: anti-exemptionalism, anti-anthropocentrism, limits to growth, balance of 
nature and eco-crisis.

\section{Reference Paradigms}

The environmental sociology was founded in the late 1970s in the United States as a branch of sociology. It is called alongside the other social sciences, with which the new discipline immediately intended to dialogue and interchange in the framework of the environmental crisis emerging at that time. Investigating complex phenomena that are abruptly imposed on the contemporary societies is necessary to recognize the conditioning effect of biophysical factors on human societies and the consequent, relationship between natural systems and social systems. In this regard, Western societies have been oriented - as far as the relationship with nature is concerned - to an optimistic perspective based on the blind belief in the human ability to make unlimited progress and social development. In this perspective humans have exceptional characteristics as culture, communication, language and technology that mark inherent differences with the other living species.

Sociology, which appears to be "one of the fundamental components of Western culture [...]" (Beato 1998a, p. 40), is pervaded, in its many theoretical configurations, by a radical anthropocentrism that "[...] essentially affirms a position of centrality in man and ends up justifying in the historical forms it has assumed, the widespread thesis [...] of man's supremacy over all other living species [...]" (Beato 1998a, p. 221). This anthropocentric attitude, from which the underlined misunderstanding of the influence of the natural environment on social organization systems, has been regarded as an obstacle to sociological reflection.

In order to open sociology to a profound debate on environmental crisis and its resulting problems, a new paradigm enabling social science with a full consideration of the complex relationships between man-nature and society-environment is increasingly required. This new paradigmatic proposition can be found in the new ecological paradigm of Catton and Dunlap, consisting of four propositions as reported below:

1. Taking on the nature of human beings. Although humans have exceptional characteristics (culture, technology, etc.), they remain one of the many other species that are interdependent in the global ecosystem.

2. Social causation: the human events are influenced by social and cultural factors, but also by complex cause-effect and feedback links in the natural environment. Therefore, intentional human actions can produce many unforeseen consequences.

3. The context of human society. Human beings live in, and depend on, a finished bio-physical environment that imposes powerful physical and biological limitations;

4. Taking on the constraints placed on human society. Although the human kind's inventiveness, and the resulting powers, seems to allow for a temporary expansion of the load capacity limits, the ecological laws cannot be overturned. 


\section{Mll Macrothink}

The influence exerted by international environmentalist orientations on Catton and Dunlap' s theoretical contribution is clearly outlined by the significant role attributed to the concept of carrying capacity which denotes the inevitable underdevelopment of human societies to the limits imposed by the natural bio-physical environment and the unquenchable cogency of the ecological laws. The notion of 'carrying capacity' is a fundamental assumption of the two author's paradigm (Beato, 1999). Moreover, as Beato (1998b) points out, ecological and positivist objectivism of the New Ecological Paradigm by Catton and Dunlap has to be integrated with inherent considerations on social actors and their semantic-definitional activities formulated in relation with the natural environment in which they live.

The social structure, in fact, cannot be described and interpreted separately from the consideration of such a dimension; nevertheless, claims-making activities of social actors cannot be investigated without reference to the social, historical-political and environmental context, which constitutes the objective reality in which they arise (Beato, 1998b). Thus, it is from the recognition of the ineligibility of the actors by the social system that the complex work of overcoming dualism between the structural and the definitional approach - which would otherwise jeopardize the evolutionary path of young environmental sociology - may suggest the importance of a thorough integration of the two approaches. A reasonable compromise is to recognize that the research interest of the environmental sociology is not focused only on the relationships between humans and their environment, but also on the ways through which these relationships are influenced by socio-cultural processes, cultural representations, collective definitions, formulation of claims, political power and public controversies (Dunlap et al., 2002). In this sense, it is useful to briefly present the model which, considering the interconnections existing between natural and social systems constitutes the analytical framework of the environmental sociology.

The analytical structure proposed by Catton and Dunlap, describes the action of a given society applied to its constituent elements as population, technology, cultural system, social system and personality system, natural environment; coherently, the environmental sociology describes the influence of the biophysical environment on "social complex systems". This framework appears to have a circular causative structure, according to the sequence: social system $\rightarrow$ environment $\rightarrow$ social system, as it highlights "[...] a process of social causation of environmental change [...] whose effects fall upon the structures and processes of society" (Beato, 1998, p. 152).

Moreover, contemporary societies are aware of the negative impacts of their activities on natural systems (the so-called anthropogenic pressure on the environment) and the outbreak of the environmental crisis as a socio-political problem, to "[...] elaborate, in turn, of "responses" both in terms of structures and mechanisms of causation as well as of the effects of environmental change [...]" (Beato, 1998, p. 152).

\section{Other Theoretical Perspectives}

The scientific debate arising from the theoretical framework by Catton and Dunlap does not 
shadow other relevant approaches that have been a common heritage of the environmental sociology (Finocchiaro 1992). Buttel (1987) spoke of a "vibrant esprit de corps" for environmental sociology (Beato, 1998, p.466), referring to the late 1970s, a period during which environmental sociologists have sought the reorientation of the discipline towards a more holistic perspective that conceptualized the social processes within the context of the biosphere.

Unlike Catton and Dunlap, Schnaiberg (1980) did not reject the theoretical-conceptual framework of classical sociology, giving value to the nineteenth-century political economy and Marxism to analyze the relationships that different societies can establish with the environment. The Schnaiberg's notion of the environment is not grounded on the social environment or the subjective environment of the individual, but refers to physical environment (air, water, soil), as it is defined by ecological disciplines. As a prominent exponent of the political economy orientation, Schnaiberg devoted considerable attention to "the complex interaction between political factors and economic factors, between the dynamics of the state and those of the 'market' [...]" (Ferrera 1989, p. 451), emphasizing the mutual influence between social systems and the biophysical natural systems and hence the need to investigate them as set of bidirectional relationships.

Schnaiberg' s sociology encompasses the notion of the treadmill of production, referring to the logic of capitalist industrial production which, with its mechanisms promoting economic growth and private capital accumulation, is directly associated with the ecological crisis. According to Schnaiberg, the trend towards growth is due both to the competitive nature of capitalism, which induces entrepreneurs to expand their activities and their profits for fear of being overwhelmed by competitors, and to the logic of complementary economic development within the sphere of the state (Buttel, 1996). In fact, in order to ensure the entry of taxes and to increase the likelihood of re-election, the State undertakes expenditure to subsidize production costs and to promote the accumulation of private capital.

However, automation, unemployment and demand for job creation or welfare state resulting from intensified capital growth, impose growing public costs and encouraged the capital accumulation in the private sector in order to provide employment and to ensure public income to pay for "social costs". Since this process of accumulation entails a continuous extraction of natural resources and contributes to pollution, it is apparent that the treadmills of production conflicts with the environment are seriously compromising the ecosystem equilibrium (Buttel, 1996).

At the same time, the most striking case of conversion to the new ecological, natural and systemic culture is undoubtedly the framework provided by Edgar Morin. According to this author, the ecological paradigm, which focuses on both system-organization and self-relationship, is an example of a correct relationship between science and ethics. Specifically, it would harmonize the responsibilities of subjects, complex phenomena, and the environmental system. In this sense, ecology would become the first science able to emulate the relationship between humans and nature and to consider humans as involved in nature Morin, 1977). In this perspective, the ecological paradigm appears to reject any single-factor 
explanatory issue (Beato, 1998b). Indeed, ecology focuses on the interaction between a plurality of components which are no longer regarded as separate entities, but "[...] as the interacting dimensions of a single complex and multidimensional object" (Morin, 1988, 127).

This approach has provided "[...] a great suggestion for building an integrated science of the environment in which nature-culture separation tends to crumble" (Morin, 1988, 127). Moreover, ecology - to which the sociological school of human ecology developed in the 1920s based on the theoretical and empirical work by Park, Burgess and McKenzie has been explicitly inspired - has been configured "[...] as a possible synthetic, architectural super-science, able to organizing the knowledge of a wide variety of disciplines, both social and natural, in an unitary theoretic framework of great breath holistic and macroscopic [...]" (Strassoldo, 1993, p. 281). As Strassoldo pointed out, this possible definition of ecology in terms of "superstitiousness", similar to what had been claimed by urbanism some decades earlier and, a century before in the contribution of Comte (1854), poses interesting problems of epistemology of science. However, the semantic reflection remains in the background because little touched by the debate concerns the theoretical and conceptual foundations of the discipline and, much more profoundly, its epistemological status (Pieroni, 2002).

\section{Understanding Landscape Complexity and Society}

Landscape can be considered as a product of the sedimentation of social and economic relations that have contributed to shape and drive territorial transformations throughout the history. The constituting elements are a latent expression of the relationship between humans and nature and, at the same time, bear witness to the slow transformation that characterizes it. The drastic changes in the use of the land that have took place over the past century in Europe - and above all in the north of the Mediterranean basin - have accelerated landscape transformations because of (i) urbanization, (ii) infrastructural development, (iii) agricultural intensification and (iv) land abandonment. Particular attention deserves peri-urban land that undergoes a continuous metamorphosis through the stratification of multiple elements.

In Mediterranean Europe, this processes primarily involved low quality land such as pastures, abandoned fields and marginal areas, impacting landscape and biodiversity (Economidou, 1993). Only recently, due to the spread of dispersed urbanization, high-quality rural areas have also undergone profound changes in land-use, with implications for landscape structure, overall ecological quality and bio-diversity. This led to a progressive destruction of the traditional landscape elements with the spread of conflicts among socioeconomic actors. A typical example is given by traditional rural landscapes along the sea coast or around major cities in southern Europe (Couch et al., 2007). The peri-urban areas of Rome, Naples, Athens, Barcelona or Lisbon, just to mention the largest cities in the Mediterranean basin, are representative of the different socioeconomic contexts that shape traditional rural landscapes undergoing urban expansion.

Preserving the peri-urban landscapes through the attenuation of social conflicts can be seen as a mean of conservation of the cultural history of the Mediterranean basin. The analysis, the 
assessment and the resolution of conflicts through the use of local resources are some of the tools that allow for the restoration of an appropriate ecological, social and economic balance, which is nowadays threatened by unregulated anthropogenic pressure. In order to reduce the impacts within landscapes rich in local diversity, the traditional farming practices and the re-use of existing resources and landscapes represent possible solutions. Facing with the challenges posed by climate changes, water scarcity and food security (Soulard et al., 2017), it is possible to state that farmers are the engine of both vulnerability and resilience of peri-urban territories: the enhancement of pre-existing rural elements and a careful exploration of the key role of farmers, becomes indispensable for soil protection. In this regard, it is essential to evaluate with a quantitative approach i) farmers' resilience, ii) characteristics of active farms, iii) conflicts that can arise with the other uses of land and iv) interrelations with the neighboring urban markets (Galli et al., 2010).

The present study contributes to the integration of agro-environmental quality indicators in support of national and European policies with locally-provided farm information, intended as witnesses of traditional knowledge and traditional culture. In this sense, the socioeconomic characteristics of the farms become an expression of the productive, social and environmental dynamics of the local territory. At the same time, farmers' behaviors are proxies of conflicts that are often generated in (ecologically and socially) degraded environments.

\section{Logical Framework and Contextual Analysis}

Peri-urban agriculture represents an economic, political, social, environmental and cultural activity with peculiar features, created by continuous contact with the adjacent urban sphere (Birks et al., 1988). Urbanization processes are intertwined with those of ruralization generating multiple conflicts. In order to better understand this phenomenon, the metropolitan region of Attica, which includes the Athens' basin in Greece, has been chosen for its typically compact urban form and for rapid transition to urban dispersion. Attica extends a total area of $3000 \mathrm{~km}^{2}$. The boundaries of the metropolitan area are those considered by the Urban Atlas project (European Environment Agency, 2010), which includes all the continental municipalities belonging to the Attica administrative area, including the Salamina island. Surrounded at the north by mountain ranges (Parnitha, Pastra and Pateras), the region comprises three coastal plains (Mesogeia, Thriasio and Marathon), which are $20 \mathrm{~km}$ away from Athens. These traditional rural areas, characterized by forests, rain-fed crops (grain, olive trees, vineyards) and irrigated crops (horticultural crops, other fruit trees) are threatened by urban and infrastructure extension, tourism and industrial development, as well as by intensive agricultural practice in rural areas.

Particular attention deserves the rural elements that characterize this area, such as the abandoned irrigation basins (Di Bartolomei et al., 2013), which represent an informal response to climate aridity (average annual rainfall below $400 \mathrm{~mm}$ and average annual air temperature of $19^{\circ} \mathrm{C}$ ). Up to the early $1990 \mathrm{~s}$, these small reservoirs represented the main source of irrigation for agricultural crops in the area. Rapid urban expansion, which has invested the area over the last 15 years, led to the abandonment of cultivated land, 
determining the abandonment of the reservoirs and, in some cases, their destruction. Open reservoirs for irrigation are considered among the most peculiar landscape elements of Athenian rural culture, together with the archaeological sites, the typical villages, the traditional agrarian landscapes. They are constantly threatened by wildfires, soil sealing, desertification and the recent processes of sprawl, contributing to fragment the relict wooded areas and the cultivated hilly areas.

Going deeper into the conflicts and threats generated by the rapid transformations that have invested local soils, the employment of quantitative indicators reflecting behaviors of several actors operating in these contexts, allows to define an interpretative framework evaluating the effect of these changes. At the same time it is possible to define possible solutions contemplating the use of the existing landscape elements and the resources of the territory.

\section{Discussion}

Evaluating socioeconomic local contexts through interviews carried out by the authors within a small group of farmers in the study area, allowed to understand i) mechanisms of farmers' resilience, ii) farm functional aspect from a joint socioeconomic point of view, and iii) major threats and conflicts emerging from local contexts. Farmers have outlined how threats to farming are mainly of environmental origin: while urban expansion appears a problem due to land speculation (determining agricultural abandonment), other conflicts may arise in the interaction with other resident population. These conflicts can specifically arise between resident and nomadic populations from Asia Minor which have informally occupied the abandoned land for farm/settlement purposes. Another problem of the area consists in the wildfires that may cause the partial (or even complete) destruction of the harvest in the summer months both in the forest area and in the nearby agricultural areas. This condition has adverse effects on the local economy, preventing farmers to provide food to proximity markets.

Farmers' awareness is also directed to climate change and, in particular, to the reduction of local water availability, that is an indispensable element for the survival of the farm itself. Climate change is accompanied by soil degradation and soil erosion caused by intense rainfalls. In this regard, a preliminary investigation carried out by the authors has highlighted a progressive return of the population to the primary sector and the elements that characterize it. The new farmers in the area have tried to solve the conflict in the use of the water through the restoration of some irrigation reservoirs. Collecting the rainwater during winter, is a measure mitigating the existing conflicts for natural resources, enhancing the sustainable use of land versus the inherent degradation of the landscape.

In these systems, representative of their complexity between human and nature, the new farmers seem rather prepared to reduce some possible conflicts in land management. It also emerges from interviews that farmers demonstrate ability to manage and control potential external threats and conflicts linked with social nature and migration flows. Farmers seem also to deal effectively with the latent consequences of the 2007 economic recession, 
implying a reduced market demand.

Generally, the urban-rural interface reflects a specific landscape resulting from the progressive connection between the agrarian landscape and the functional structure of urban areas. A comprehensive understanding of the intimate characteristics and quality of the rural landscapes that interfaces with the Athens' urban area is linked to a careful analysis of the exogenous and endogenous elements reflected in the farm's structure and in the relationships with the surrounding population.

The ability of new farmers to integrate with the nomadic realities in the area and to put in place measures to counteract the considerable threats to crop production is a positive aspect for the local economy. At the same time, the rediscovery of rural elements characterizing local productions and the typical Greek rural landscape, such as the irrigation reservoirs outlines the intrinsic role of landscape element that imply conservation of the landscape both from historical (archaeological sites), cultural (typical villages), ecological and environmental point of view. Thus, a new role for farmers is consolidating in the area, representing a social force able to manage environmental challenges through the optimization of existing local resources.

The unpredictability of the ongoing environmental changes, coupled with the rapid evolution of contemporary landscapes, determines macroscopic and severe effects on the local communities. The consequences are obvious in many peri-urban areas, especially those characterized by fragile ecosystems. Climate change is impacting these sensitive contexts and, in addition to environmental concerns; it also involves the social dimension, presenting a non-negligible bill in economic terms.

Environmental sociology interprets these changes through a holistic vision which is added to the more traditional interpretations provided by ecological and geographical disciplines. In this regard, considering the landscape-climate-soil elements as a highly complex system, concepts such as change, variability, anomaly, and balance must relate to non-individual and finite territorial spheres. The individual magnitudes can be measured through the global involvement of each variable and the existing cause-effect interrelations (Conacher, 2000).

In order to cope with this emergence, which is at the same time significant at global and local levels, a preventative approach - based on scientific knowledge - is essential: in this sense is necessary to enabling the decision-makers to develop the most effective environmental policies and to feed and stimulate public debate. Therefore the knowledge and the systematic monitoring become fundamental both in order to manage land resources and to prevent (or mitigate) the effects of activities that lead to degradation of the landscape.

In this context, tools assessing the relationship between the territory (with its multiple expressions of economic space in mutation) and complex social systems are needed: environmental degradation is witnessed by significant and often disastrous events worldwide (Perini et al., 2008). In this regard, the centrality of scientific approaches have to be emphasized, integrating knowledge derived from deterministic modeling and quantitative analysis with descriptive, explorative, narrative-perspective techniques able to identifying 
pathways of territorial development and latent change variables.

In a policy perspective, the interventions aimed at making a landscape transformation sustainable can be applied producing satisfactory results in mitigating degradation phenomena both in recently transformed peri-urban areas and in typically rural area: these transformations are successful only if the operators perceive such phenomena as a support to profitability. In this sense, a quantitative approach can better capture this aspect considered crucial for effective local-scale implementation of measures containing environmental degradation. Moreover, these measures are more timely in those areas where agricultural production represents a relevant income.

National and regional policies and the awareness of local actors, combined with a more complete understanding of environmental phenomena, can effectively counteract trends in place through targeted action plans in a context of organic and coordinated measures (Wilson $\&$ Juntti, 2005). The cultural change in favor of a widespread environmental awareness requires the active involvement of both the scientific and productive world and the political and social forces and civil society, through a democratic participation in the decisions, possibly supported by analysis of various kinds and carried out with mixed and inclusive techniques that can deepen the complexity of socio-environmental systems.

\section{References}

Atav, E., Altunoğlu, B. D., \& Sönmez, S. (2015). The determination of the environmental attitudes of secondary education students. Procedia - Social and Behavioral Sciences, 174, 1391-1396. https://doi.org/10.1016/j.sbspro.2015.01.765

Birks H. H., Birks H.J.B., Kaland P.E., \& Moe D. (1988). The cultural landscape: past, present and future. Cambridge: Cambridge University Press.

Couch C., Petschel-held G., \& Leontidou L. (2007). Urban Sprawl In Europe: Landscapes, Land-use Change and Policy. London: Blackwell. https://doi.org/10.1002/9780470692066

Di Bartolomei R., Salvati L., \& Zitti M. (2014). Elementi per un paesaggio resiliente? Irrigazione, degrado del suolo e agricoltura nel peri-urbano senza piano. Memorie Geografiche, 2, 245-249.

Economidou E. (1993). The Attic landscape throughout the centuries and its human degradation. Landscape and Urban Planning, 24, 33-37. https://doi.org/10.1016/0169-2046(93)90079-S

European Environment Agency, Urban Atlas, (2010). Retrieved from http://www.eea.europa.eu/data-and-maps/data/urban-atlas.

Galli, M., Lardon, S., Marraccini, E., \& Bonari, E. (2010). Agricultural management in peri-urban areas. In The experience of an international workshop. Gezzanho, Felice Editore. 


\section{Macrothink}

Journal of Sociological Research

ISSN 1948-5468

2018, Vol. 9, No. 1

Beato, F. (1998a). Rischio e mutamento ambientale globale. Percorsi di sociologia dell'ambiente. Franco Angeli, Milano.https://doi.org/10.4000/qds.1520

Beato, F. (1998b). I quadri teorici della sociologia dell'ambiente tra costruzionismo sociale ed oggettivismo strutturale. Quaderni di sociologia, 17(1), 41-60.

Beato, F. (1999). Parchi e società. Turismo sostenibile e sistemi locali. Liguori, Napoli.

Blaikie, P., \& Brookfield, H.C. (1987). Land degradation and society. Methuen, London.

Bonavero, P., Dematteis, G., \& Sforzi, F. (1999). The Italian Urban System. Towards European Integration. Aldershot, Ashgate.

Briassoulis, H. (2005). Policy integration for complex environmental problems. Aldershot, Ashgate.

Buttel, F.H. (1987). New directions in environmental sociology. Annual Review of Sociology13, 465-488. https://doi.org/10.1146/annurev.so.13.080187.002341

Buttel, F.H. (1996). Environmental and resource sociology: Theoretical issues and opportunities for synthesis. Rural Sociology, 61, 56-76. https://doi.org/10.1111/j.1549-0831.1996.tb00610.x

Catton, W. R. Jr., \& Dunlap, R. E. (1978). Environmental sociology: a new paradigm. The American Sociologist, 13, 41-49.

Comte, A. (1854). Système de politique positive ou traité de sociologie in Oeuvres de Auguste Comte, Vol. II, Anthropos, Paris, 1970.

Conacher, A.J. (2000). Land degradation. Kluwer, Dordrecht.

Cori, B., \& Lemmi, E. (2001). La regione mediterranea. Sviluppo e cambiamento. Patron, Bologna.

Dal Pozzolo, L. (2002). Fuori città senza campagna. Paesaggio e progetto nella città diffusa. Franco Angeli, Milano.

Dematteis, G. (2005). Territorialità, sviluppo locale, sostenibilità: il modello SLOT. Franco Angeli, Milano.

Dunlap, R. E., Michelson, W., \& Stalker, G. (2002). Environmental sociology: An introduction. Handbook of environmental sociology, 15(1), 1-32. https://doi.org/10.1177/1086026602151002

Faggi, P. (1991). La desertificazione. ETAS Libri, Milano.

Fantin, M., Morandi, M., Piazzini, M., \& Ranzato, L. (2012). La città fuori dalla città.. INU Edizioni, Roma.

Ferrera, A. (1989). Political economy e scienza politica. Un primo bilancio, in A. Panebianco (a cura di). L'analisi della politica. Bologna, il Mulino. 
Finocchiaro, E. (1992). Scienze sociali e questione ambientale. Sociologia, 2(3), 301-356.

Gagliardo, P. (2004). Desertificazione: attori, ricerca, politiche. Società Geografica Italiana, Ricerche e Studi 14.

Johnson, D.L., \& Lewis, L.A. (2007). Land degradation. Creation and destruction. Rowman \& Littlefield, Lahnam.

Kok, K., Rothman D.S., \& Patel M. (2004). Multi-scale narratives from an IA perspective: Part I. European and Mediterranean scenario development. Futures, 38, 261-284.https://doi.org/10.1016/j.futures.2005.07.001

Iosifides, T., \& Politidis, T. (2005). Socio-economic dynamics, local development and desertification in western Lesvos, Greece. Local Environment, 10, 487-499.https://doi.org/10.1080/13549830500203162

Lemon M., Seaton R., \& Park J. (1994). Social enquiry and the measurement of natural phenomena: the degradation of irrigation water in the Argolid Plain, Greece. International Journal of Sustainable Development and World Ecology, 2(3), 1-11. https://doi.org/10.1080/13504509409469875

Martinelli, F. (1981). Città e campagna. La sociologia urbana e rurale. Liguori Editore, Napoli.

Mela, A., Belloni, M.C., \& Davico, L. (1998). Sociologia dell'ambiente. Carocci, Roma.

Morin, E. (1977). La méthode, Tome 1: la nature de la nature. Seuil, Paris, 377, 8.

Morin, E. (1988). Pensare l'Europa. Feltrinelli, Milano.

Oxley, T., \& Lemon, M. (2003). From social-enquiry to decision support tools: towards an integrative method in the Mediterranean rural environment. Journal of Arid Environment, 54, 595-617. https://doi.org/10.1006/jare.2002.1082

Onate, J.J., \& Peco, B. (2005). Policy impact on desertification: stakeholders' perceptions in $\begin{array}{lllll}\text { southeast Spain. Land } & \text { Lolicy,22, } & \text { 103-114. }\end{array}$ https://doi.org/10.1016/j.landusepol.2004.01.002

Patel, M., Kok, K., \& Rothman, D.S. (2007). Participatory scenario construction in land use analysis: an insight into the experiences created by stakeholder involvement in the Northern Mediterranean. Land Use Policy, 24, 546-561. https://doi.org/10.1016/j.landusepol.2006.02.005

Perini, L., Salvati, L., Ceccarelli, T., Sorrenti, S., \& Zitti, M. (2008). La desertificazione in Italia. Bonanno, Roma-Acireale.

Pieroni, O. (2002). Fuoco, acqua, terra e aria. Lineamenti di una sociologia dell'ambiente. Carocci, Roma.

Quaranta, G., \& Salvia, R. (2005). Riqualificazione e gestione del territorio, lotta alla desertificazione e sviluppo sostenibile. Buone pratiche per $i$ territori rurali. 
FrancoAngeli, Milano.

Schnaiberg, A. (1980). The Environment: From Surplus to Scarcity. Oxford University Press, New York.

Sereni, E. (1961). Storia del paesaggio agrario italiano. Laterza, Roma-Bari.

Soulard, C. T., Valette, E., Perrin, C., Abrantes, P. C., Anthopoulou, T., Benjaballah, O., \& Marraccini, E. (2017). Peri-urban agro-ecosystems in the Mediterranean: diversity, dynamics, and drivers. Regional Environmental Change, 1-12.https://doi.org/10.1007/s10113-017-1102-z

Strassoldo, R. (1977). Sistema e ambiente. Introduzione all'ecologia umana. Franco Angeli, Milano.

Strassoldo, R. (1993). Le radici dell'erba. Liguori, Napoli.

Trisorio, A. (2005). Misurare la sostenibilità. Indicatori per l'agricoltura italiana. Istituto Nazionale di Economia Agraria, Roma.

Turri, E. (1999). La megalopoli padana. Marsilio, Venezia.

Wilson, G.A., \& Juntti, M. (2005). Unravelling desertification: policies and actor networks in Southern Europe. Wageningen Academic Publishers, Wageningen. https://doi.org/10.3920/978-90-8686-559-8

\section{Copyright Disclaimer}

Copyright for this article is retained by the author(s), with first publication rights granted to the journal.

This is an open-access article distributed under the terms and conditions of the Creative Commons Attribution license (http://creativecommons.org/licenses/by/3.0/). 